IZA DP No. 9668

Discouraged Immigrants and the Missing Pop in EPOP

Peter Norlander

Todd A. Sørensen

January 2016

Forschungsinstitut

zur Zukunft der Arbeit

Institute for the Study

of Labor 


\title{
Discouraged Immigrants and the Missing Pop in EPOP
}

\author{
Peter Norlander \\ Loyola University Chicago \\ Todd A. Sørensen \\ University of Nevada, Reno \\ and IZA
}

\section{Discussion Paper No. 9668 \\ January 2016}

\author{
IZA \\ P.O. Box 7240 \\ 53072 Bonn \\ Germany \\ Phone: +49-228-3894-0 \\ Fax: +49-228-3894-180 \\ E-mail: iza@iza.org
}

\begin{abstract}
Any opinions expressed here are those of the author(s) and not those of IZA. Research published in this series may include views on policy, but the institute itself takes no institutional policy positions. The IZA research network is committed to the IZA Guiding Principles of Research Integrity.

The Institute for the Study of Labor (IZA) in Bonn is a local and virtual international research center and a place of communication between science, politics and business. IZA is an independent nonprofit organization supported by Deutsche Post Foundation. The center is associated with the University of Bonn and offers a stimulating research environment through its international network, workshops and conferences, data service, project support, research visits and doctoral program. IZA engages in (i) original and internationally competitive research in all fields of labor economics, (ii) development of policy concepts, and (iii) dissemination of research results and concepts to the interested public.
\end{abstract}

IZA Discussion Papers often represent preliminary work and are circulated to encourage discussion. Citation of such a paper should account for its provisional character. A revised version may be available directly from the author. 
IZA Discussion Paper No. 9668

January 2016

\section{ABSTRACT}

\section{Discouraged Immigrants and the Missing Pop in EPOP*}

We address the impact of declining migration on the measurement of labor market health. We first document an historically significant decline in the growth rate of the U.S. foreign born population since 2000. A decomposition shows that nearly two-thirds of the decline can be attributed to declining pull factors in the U.S. Had this decline not occurred, there would have been approximately 7.2 million more immigrants present in the U.S. in 2013. Making a conservative assumption about the hypothetical likelihood of employment for these "Discouraged Immigrants," a recalculation of the Employment to Population Ratio reveals a $13 \%$ larger decline since 2000 than is shown when conventionally measured.

JEL Classification: J21, J61

Keywords: employment data, population, international migration

Corresponding author:

Todd Sørensen

Department of Economics

University of Nevada, Reno

Ansari Business Building 318

1664 N. Virginia Street

Reno, NV 89557

USA

E-mail: tsorensen@unr.edu

\footnotetext{
* We are grateful for feedback received at a seminar at the University of Nevada Reno, the labor lunch at the University of California, Santa Barbara and the Southern Economics Association. We also acknowledge valuable feedback and insight from Briggs Depew, Sankar Mukhopadhyay, and Jeanne Wendel.
} 


\section{Intro}

Labor market indicators may mask underlying trends in labor markets. Hotchkiss (2014) argues that the Employment to Population Ratio (EPOP) should be adjusted for demographic changes in labor supply. Autor and Duggan (2003) document increased exits from the labor force through take up of disability insurance, and Autor et al. (2013) link this phenomenon to heavier import competition. When workers disappear from the labor force, they become "invisible," as Autor has called them, are not counted in conventional measures of labor market health, and may indicate a declining U.S. labor market. ${ }^{1}$

In this paper, we document an historic decline in immigration to the U.S., its creation of similarly "invisible" immigrants, and consequences for measurement of EPOP. A working paper by Depew, Norlander and Sørensen (2013) first explores this issue when discussing a finding of cyclical return migration. Here, using a novel approach, we decompose a recent slowdown in the growth rate of the foreign born population into U.S. specific (pull) and origin specific (push) factors. Changing pull factors account for between $60 \%-65 \%$ of the decline. We refer to the approximately 7.2 million immigrants who have not arrived in the U.S. on account of declining pull factors as Discouraged Immigrants, and show how the conventional measure of EPOP may have missed around $13 \%$ of the decline in the labor market since 2000 .

\section{Analysis}

We first examine the decline in the growth rate of the foreign born population residing in the U.S. The left panel of Figure 1 displays annualized growth rates of the stock of the adult foreign born population from 1900 to 2013, while the right panel displays changes in this growth rate. ${ }^{2}$ In the period 2000-2013, the growth rate was $2.5 \%$, representing a 2.1 percentage point decline from the 19902000 growth rate. The historic significance of this decline becomes clearer when we consider the context of previous changes in the growth rate. Relatively liberal immigration policy bookends a more restrictive period between two substantial regime changes: the passage of the restrictive Immigration Act of 1924 and the liberalizing Immigration and Nationality Act of 1965 (Borjas, 2001, 40). The regime breaks are marked by vertical lines, and the first decades to be partially and fully affected by the break are marked with red dots. In the right panel, the red horizontal line shows that the average regime break period (one of which encompassed most of the Great Depression) experienced a 1.8 percentage point change in the absolute value of the growth rate. The blue horizontal line shows that, in contrast, other pre-2000 periods experienced on average less than a 0.6 percentage point change in the absolute value of the growth rate. Thus, the 2.1 percentage point decline in the growth rate since the 1990s is much more similar to a regime break period than it

\footnotetext{
${ }^{1}$ See http://www.thisamericanlife.org/radio-archives/episode/490/transcript

${ }^{2}$ These figures are obtained using Ruggles et al. (2010). Details are available in the data appendix.
} 
is to a standard period. ${ }^{3}$ It also represents the greatest decline for all periods we study.

This decline could have been caused by changes in push or pull factors. On the pull side, Villarreal (2014) shows that depressed U.S. labor demand has lowered post Great Recession migration from Mexico. Immigration policies in the U.S. may also have contributed to the decline. On the push side, Hanson and McIntosh (2010) show that lagged declines in Mexican fertility partially account for recent declines in Mexican immigration to the U.S. Here, we present a strategy to decompose the 2.1 percentage point decline into portions attributable to changing push and pull factors. Using 2000 census data, we study migration flows to the U.S. from around the world by grouping immigrants into 43 places of birth (that accounted for around $90 \%$ of immigrants) and one additional "other" origin. For each origin $j$, we regress the log count of immigrants, $m_{j}$, in 1970, 1980, 1990, 2000 and 2013 on the log count of immigrants from the remaining 43 countries of birth $\left(M_{-j}\right){ }^{4}$ The predicted value of $m_{j}$ is driven by factors in all countries other than $j$, and thus is purged of push factors specific to $j$. Predicting the log count in each regression and exponentiating the sum creates $\hat{M}$. Changes in $\hat{M}$ from one period to the next can then be interpreted as the pull-driven growth rate.

While this approach should purge country-specific push factors, region-specific push factors may still be present in our estimates. In other words, predicting Mexican migration with Salvadoran migration may be problematic, as Mexico and El Salvador may be experiencing similar push-driven factors. To address this concern, we repeat the above regressions, this time putting more weight on the migration stock from more distant countries. We construct $M_{-j}^{d}=\sum_{i \neq j} m_{i} \times d_{i j}$, where $m_{i}$ is the $\log$ count of immigrants from country $i$ and $d_{i j}$ is the distance between countries $i$ and $j$. Thus, when predicting Mexican migration, we now put more weight upon Chinese migration than Salvadoran migration.

We summarize the results of this analysis in Table 1. The second column of the table displays the raw annualized growth rate, which has declined from $4.58 \%$ in the 1990 s to $2.50 \%$ since 2000 . In the third-column, the pull-driven estimates without distance weights show a decline from $5.60 \%$ to $4.24 \%$, while the distance weights approach yields an estimated decline from $5.48 \%$ to $4.24 \% .^{5}$ These three respective

\footnotetext{
${ }^{3} \mathrm{~A}$ Mann-Whitney test, treating all estimates as population parameters, fails to reject the null when comparing the 2000-2013 growth rate to the four regime break observations with a p-value of .4795 , and narrowly fails to reject when comparing to the seven nonregime break observations, with a p-value of .1266.

${ }^{4}$ We begin our analysis in 1970, as it is the first census year after the liberalizing Immigration and Nationality Act of 1965. Because the Great Recession only ended in June of 2009, using data from 2010, rather than 2013, would have produced more dramatic results. Further, we repeat our analysis using only 1970-2000 and show the robustness of this exclusion in the appendix.

${ }^{5}$ Note that our estimates showing lower observed growth rates than estimated pulldriven growth rates imply that the push-driven growth rate is negative: without positive growth in labor demand for immigrants in the U.S., declining push factors in sending countries would actually yield a contraction in the stock of the foreign born in the U.S.
} 
declines of 2.08, 1.36 and 1.24 percentage points suggest that it is important to account for country-specific push factors, but that accounting for additional regionspecific push factors does not substantially change our estimated growth rates. Thus, we conclude that $60 \%-65 \%$ of the drop in the growth rate is attributable to declining pull factors. ${ }^{6}$

We proceed to analyze the decline in migration since 2000 with four different growth rates. ${ }^{7}$ First, we consider the observed 1990s growth rate of $4.58 \%$. Second, we consider the actual growth rate of $2.5 \%$. Finally, we create two additional growth rates that reflect declines in pull-driven migration. A rate of $3.86 \%$ reflects a counterfactual growth rate for the post 2000 period, in which the 1.36 percentage point pull-driven decline did not occur and is added to the baseline $2.5 \%$ growth. Repeating this calculation for the distance weight approach, we obtain another counterfactual of $3.74 \%$. Figure 2 displays the immigrant stock under the four growth rates described above: a continuation of the 1990s trend growth rate would have yielded 54.10 million immigrants by 2013 , while the actual growth rate yields only 41.31 million. Thus, the observed migration stock is 12.79 million below the 1990s trend. The non-distance and distance pull-driven approaches yield 49.32 and 48.54 million immigrants, respectively. Thus, pull-driven declines yield a more modest decrease of between 8.01 and 7.23 million immigrants.

We now proceed to analyze the impact of these Discouraged Immigrants on the measurement of the EPOP. During weak labor markets, EPOP is preferred to the Unemployment Rate (UR) as a measure of labor market health. This is because attrition of discouraged (i.e. missing) workers from the labor force tends to cause artificial decreases in UR. For example, UR has rebounded $80 \%$ since the depths of the Great Recession, while EPOP has only recovered $17 \%$ of its decline. ${ }^{8}$ Our thesis is that Discouraged Immigrants will generate the same problem for EPOP as discouraged workers do for UR. Here, we consider the large 6.1 percentage point drop in EPOP between March of 2000 and 2013. What would EPOP have been if these Discouraged Immigrants actually did arrive in the U.S.? Clearly, this would add to the denominator of EPOP. If some of these individuals would have found work in the U.S., the numerator must be adjusted as well. We define $\alpha$ as the proportion of Discouraged Immigrants who would have been employed had they migrated to the U.S. A value of $\alpha=0$ places none of the Discouraged Immigrants in the numerator of EPOP, while $\alpha=.585$, the 2013 EPOP, preserves the ratio of the numerator and denominator, yielding no effect. Given that Discouraged

\footnotetext{
${ }^{6}$ Note that the raw growth rate has declined since the $1990 \mathrm{~s}$, and remains lower than its value in the 1970s and 1980s while the pull-driven growth rates have declined since the 1990s, they remain greater than the pull-driven growth rates of the 1970s and 1980s.

${ }^{7}$ In the appendix, we describe how we cross-walk between the official BLS EPOP data, which we use for baseline population estimates in Figures 2 and 3 and the ACS, which we use to study the immigrant population.

${ }^{8}$ The UR increased by 5.5 percentage points from $4.4 \%$ in March of 2007 to a March peak of $9.9 \%$ in 2010, and by March of 2015 has declined by 4.4 percentage points. EPOP declined by 4.8 percentage points from 63.3 to 58.5 between March of 2007 and 2010, but has only increased .8 percentage points to March 2015 (bls.gov).
} 
Immigrants chose not to migrate to the U.S. on account of declining pull factors, we believe that it is reasonable to assume these workers would have been less likely to have been employed than the average worker. We choose to use the midpoint between 0 and $.585(\alpha=.2925)$ in our main analysis. We extend this analysis to different values of $\alpha$ in the appendix.

Figure 3 illustrates that, under each of the three counterfactual growth rates, the standard measure of EPOP has underestimated the weakness of labor markets since 2000. The left panel of Figure 3 displays the change in EPOP year by year, while the right panel compares the total decline between 2000 and 2013 across growth rates. The decline from the straightforward extrapolation of the 1990s growth rate was 7.6 percentage points, $24.6 \%$ greater than the baseline decline of 6.1 percentage points. This decline drops to 7.0 and 6.9 percentage points when we focus on the pull-driven decline in migration. Thus, even in the most conservative case, factoring Discouraged Immigrants back into the equation suggests a decline in EPOP over $13 \%$ larger than at the baseline.

\section{Conclusion}

We document that the decline in the growth rate of the immigrant population since 2000 is the largest in our period of study which dates to the turn of the 20th Century. We disentangle push and pull changes in the growth rate. Our most conservative estimate finds that a decline in pull factors specific to the U.S. has created over 7 million Discouraged Immigrants. Just as discouraged workers hamper UR as a measure of labor market health, Discouraged Immigrants affect the measurement of EPOP, and suggest that the overall decline in labor demand may have been greater than conventionally measured. This provides further evidence of the severity of the deterioration in the labor market since 2000. 


\section{References}

Autor, David H. and Mark G. Duggan, "The Rise in Disability Rolls and the Decline in Unemployment," The Quarterly Journal of Economics, February 2003, pp. 157-205.

_ , David Dorn, and Mark G. Duggan, "The China Syndrome: Local Labor Market Effects of Important Competition in the United States," The American Economic Review, 2013, 103 (6), 2121-2168.

Borjas, George J., Heaven's door: Immigration policy and the American economy, Princeton University Press, April 2001.

Depew, Briggs, Peter Norlander, and Todd A. Sørensen, "Flight of the H1B: Inter-Firm Mobility and Return Migration Patterns for Skilled Guest Workers," June 2013, (7456).

Hanson, Gordon and Craig McIntosh, "The Great Mexican Emigration," Review of Economics and Statistics, November 2010, 92 (4), 798-810.

Hotchkiss, Julie L., "Adjusted EPOP as an Indicator of Labor Market Strength," Research in Applied Economics, 2014, 6 (3).

Ruggles, Steven, J. Trent Alexander, Katie Genadek, Ronald Goeken, Matthew B. Schroeder, and Matthew Sobek, "Integrated Public Use Microdata Series: Version 5.0 [Machine-readable database]," 2010.

Villarreal, Andrés, "Explaining the Decline in Mexico-U.S. Migration: The Effect of the Great Recession," Demography, November 2014, 51 (6), 2203-2228. 
Table 1: Immigrant Stock Growth

\begin{tabular}{rrrr}
\hline \hline & \multicolumn{3}{c}{ Pull Driven } \\
Period & Raw & No Dist. & Dist. Weights \\
\hline $1970-1980$ & 0.0353 & 0.0218 & 0.0233 \\
$1980-1990$ & 0.0376 & 0.0337 & 0.0337 \\
$1990-2000$ & 0.0458 & 0.0560 & 0.0548 \\
$2000-2013$ & 0.0250 & 0.0424 & 0.0424 \\
\hline Post 2000 $\Delta$ & -0.0208 & -0.0136 & -0.0124 \\
\hline \hline
\end{tabular}


Figure 1: Long Run Migration Trends

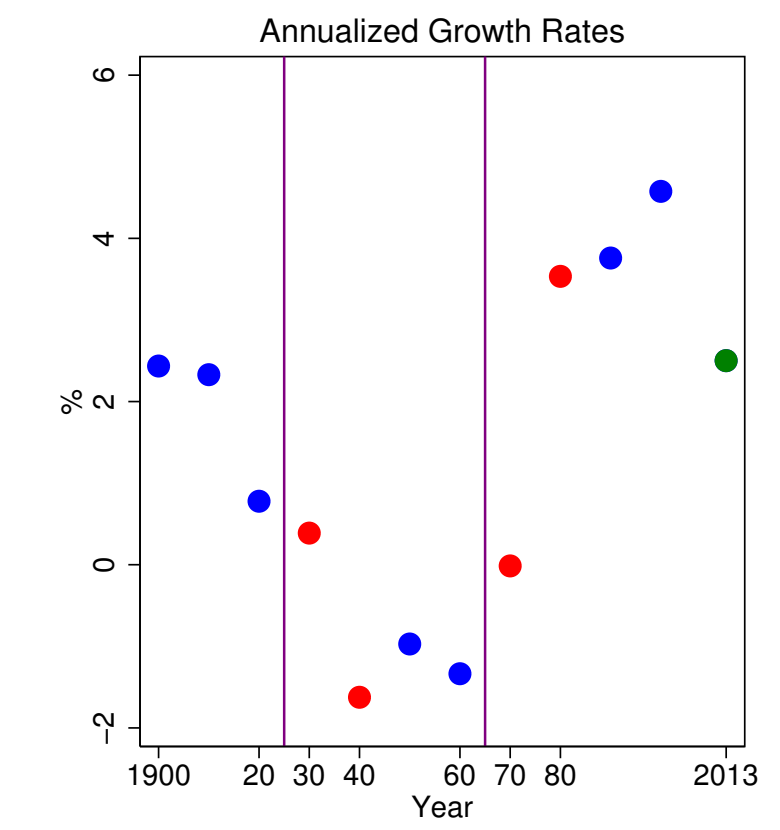

Change in Annualized Growth Rates (Abs. Value)

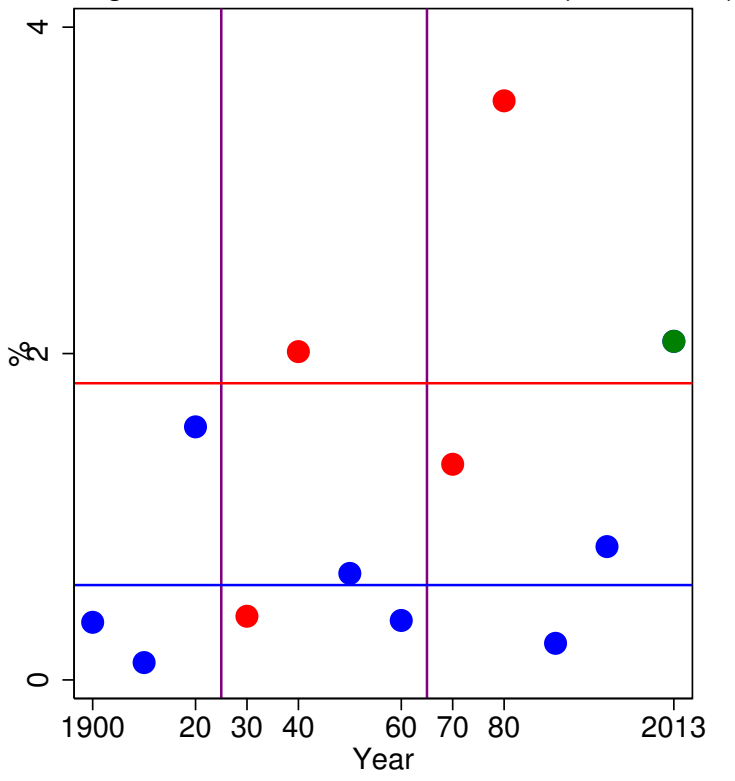

- Years Affected by Regime Breaks

- Non-Break Years

2013

Horizontal line displays averages for break and non-break years. Source: ACS. 
Figure 2: Baseline and Counterfactual Trends in Migration Stock

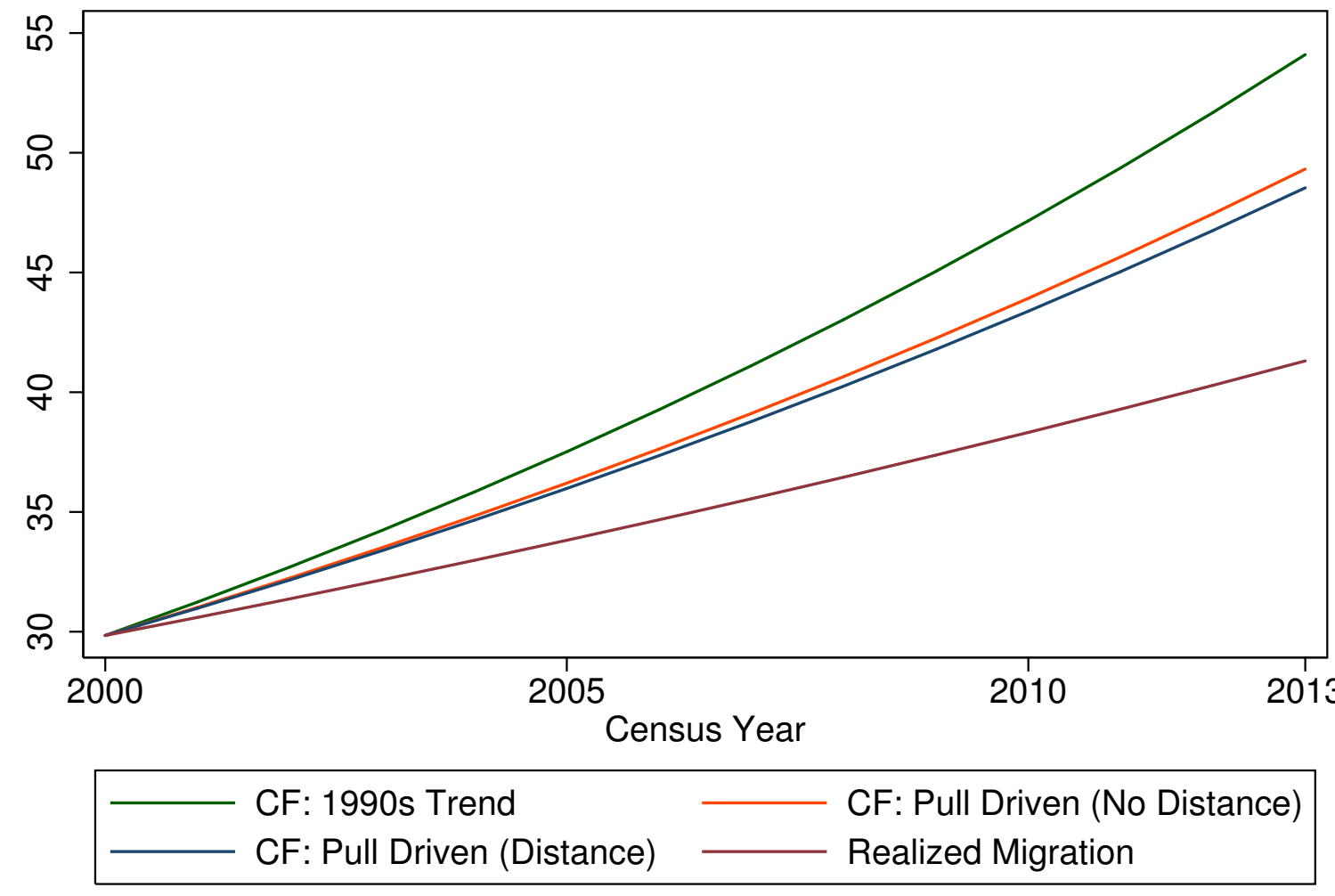

Source: ACS and BLS 
Figure 3: Baseline and Counterfactual Changes in EPOP
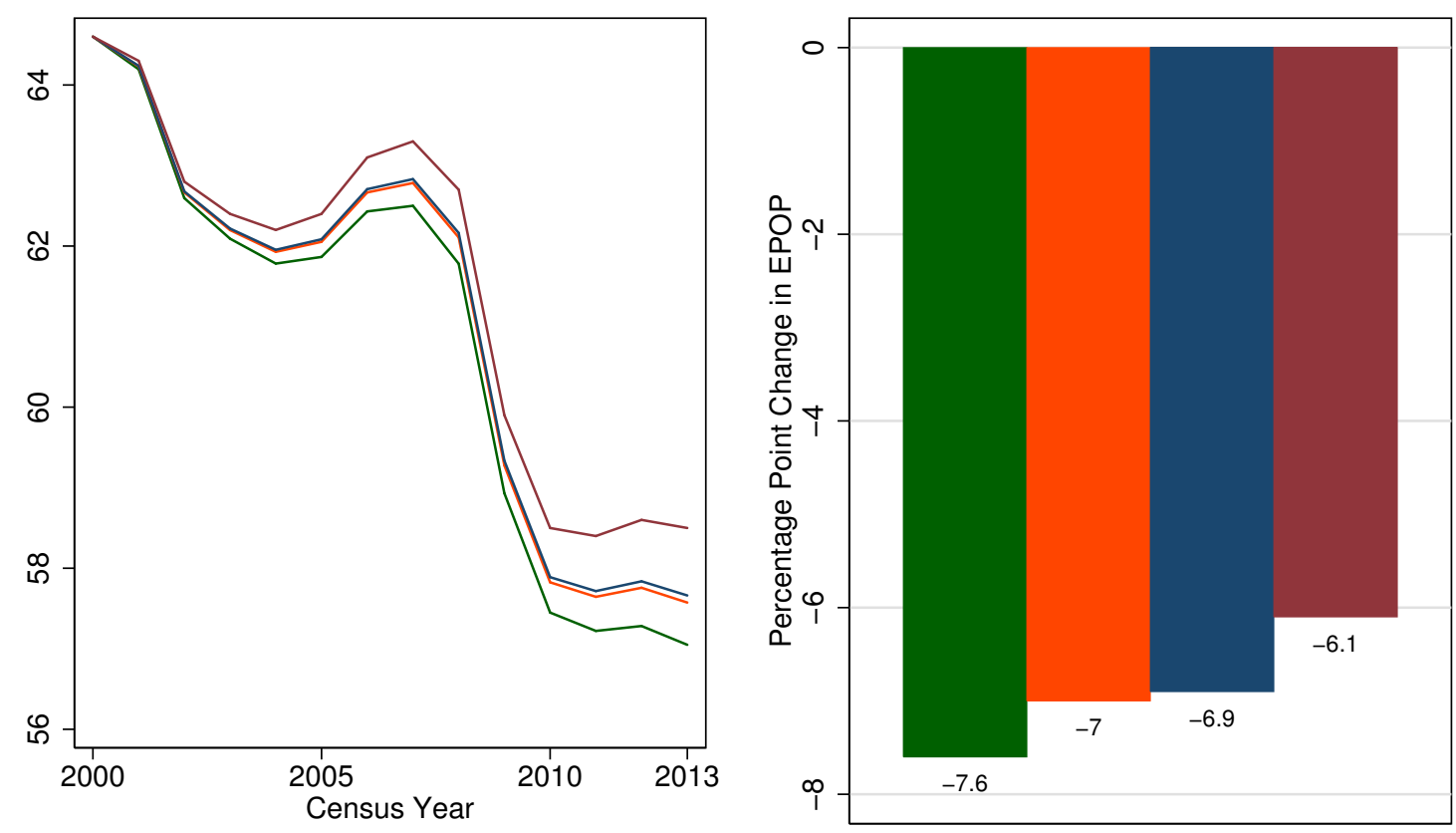

CF: 1990s Trend

CF: Pull Driven (No Distance) CF: Pull Driven (Distance) Observed EPOP

Source: ACS and BLS. 


\section{Online Appendix:}

\section{Discouraged Immigrants and the Missing Pop in EPOP}

Peter Norlander and Todd Sorensen

\section{Data Construction:}

IPUMS Census and ACS data (Ruggles et al., 2010) are used to construct the count of the immigrant population. We focus on individuals age 16 and older and exclude residents of institutions and other group quarters in all years. We use decennial censuses 1870, 1880, 1900-2000, and the American Community Survey of 2013. The 1890 census is omitted, as it was destroyed in a fire. Thus, the 1880 census is used to create the annualized growth rate reported for 1900, and the difference between this rate and the 1870-1880 growth rate is used to calculate the change in the annualized growth rate for 1900 .

A common concern with census data is that it misses undocumented immigrants. Passel et al. (2013) demonstrate a very high coverage rate of this population in the data, and document how the Census recognized the danger of undercounting in the early 2000s and made adjustments that increased the estimated size of the undocumented population by $8 \%-13 \%$ for $2000-2009,5 \%-7 \%$ for $2010-2012$, and $2 \%$ $3 \%$ since 2012 . Therefore, if undercounting is a concern, the changes in Census methodology since 2000 underestimate the size of the slowdown that we document in our paper.

For the distance-weighted pull estimates of the decline in the growth rate, we compute the distance between the centroids of each of the 43 largest immigrant sending countries using geographic data from the Portland State University Economics Department (http://www.pdx. edu/econ/country-geography-data). For the "other country" category, we use the center of world population, which is "at the crossroads between China, India, Pakistan and Tajikistan." ${ }^{1}$ We choose to use Tajikistan as its center appears to be closer to this crossroads than the centers of the other three countries.

\footnotetext{
${ }^{1}$ See Grasland and Madelin (2001) and http://en.wikipedia.org/wiki/Center_of_ population\#cite_note-3.
} 
We make the following adjustments to the country of origin: Hong Kong is assigned to China's centroid. "UK ns" is assigned to England. Census and ACS data inconsistently capture South and North Korean immigrants: we assign all Korean immigrants to the South Korean centroid. Six countries are not captured in the 1970 Census, so for all years: Guyana is assigned to Venezuela, Taiwan to China, Cambodia to Vietnam, Laos to Vietnam, Thailand to Vietnam, and "Other Africa" to Nigeria. Germany is missing in 1980, so West and East Germany are assigned to Germany for all years. Ukraine is missing in 1990, and is assigned to Russia for all years.

In order to insure an exact replication of the baseline decline in EPOP, we use the official seasonally-adjusted EPOP (BLS series LNS12300000) calculated by the BLS, which draws from the CPS civilian non-institutionalized population over the age of sixteen (LNU00000000) and the seasonallyadjusted employment level (LNS12000000).

Because the above described BLS data is not separately broken down by foreign-born and native-born populations, we estimate these populations from the larger ACS survey, and multiply the estimated foreign-born share of the non-institutionalized population age 16 and over by the official count used in the denominator of the EPOP in the year 2000. Our estimate of the foreign-born population share in 2000 is $14.102 \%$; if military personnel are excluded from this calculation, the estimated foreign-born share would be slightly higher, at $14.128 \%$. This minuscule difference of less than three hundredths of a percentage point results in an estimate of the 2000 immigrant base population that differs by about 55,000 individuals. Table A1 presents the immigrant count using the ACS while Table A3 uses the immigrant share from the ACS multiplied by the denominator of EPOP. Differences in these numbers are a result of differing base populations between ACS and BLS figures, which we attribute to differing seasonal factors and population weighting approaches.

We now describe additional supporting figures, tables, and robustness checks of our analysis. The raw data used to generate Figure 1 in the paper is presented in Table A1. Figure A1 displays the log of the stock of immigrants in the U.S. from 1870-2013 using the ACS, and indicates the "regime change" years described in the body of the paper.

Table A2 displays the population stock of immigrants from sending 
countries in 2000, as well as p-values and coefficient estimates for each distance and non-distance pull-driven weighted migration regression. Note that in the 44 distance regressions, 26 coefficients are positive at the .01 level, 36 coefficients are positive at the .05 level, and 38 coefficients are positive at the .10 level. In the non-distance weighted regressions, 27 coefficients are positive at the .01 level, 37 coefficients are positive at the .05 level, and 38 coefficients are positive at the .10 level. Figure A2 displays histograms of the p-values from the above regressions.

Tables A3 and A4 present each step of the analysis used to estimate the counterfactual EPOP displayed in the paper's Figure 3. The first column of Table A3 presents information on which scenario (raw, pull (Distance), or pull (No-Distance)) is being used, the second column displays an estimate of the actual number of immigrants in 2013. This estimate is obtained by applying the observed 2000-2013 growth rate in the stock of the immigrant population, obtained from the ACS, to the 2000 baseline population described above. When comparing this estimate for 2013 to a separate estimate for 2013 obtained by taking the BLS estimate of the relevant population, multiplied by a 2013 ACS estimate of the foreign born population, the two estimates differ by only about 42,000 individuals, or about .1 percent. The third column displays the counterfactual number of immigrants in the scenario applied, the fourth column displays the number of Discouraged Immigrants from the population used in the EPOP calculation, the fifth column displays the $\alpha$ level applied to estimate the counterfactual EPOP, and the sixth column displays the number of estimated employees missing from EPOP. The first two columns of Table A4 repeat information in Table A3. The third column displays the EPOP observed in 2013, the fourth column the counterfactual EPOP in 2013, the fifth column the actual decline in EPOP between 2000 and 2013, the sixth column displays the counterfactual decline in EPOP between 2000 and 2013, and the last column presents the ratio between the decline in the observed EPOP and the counterfactual EPOP.

Based upon the numbers reported in these tables, Figure A3 displays the ratio of the decline in each counterfactual scenario to the observed decline in EPOP under different values of alpha, the proportion of Discouraged Immigrants that would be employed. The effect of Discouraged Immigrants on EPOP declines as $\alpha$ increases: the effect 
is at a maximum at $\alpha=0$, our preferred estimate is indicated with a vertical red line at $\alpha=.2925$, no effect is seen at $\alpha=.585$, and for values of $\alpha>.585$, the effect of Discouraged Immigrants is to increase EPOP. We believe that values of $\alpha>.585$ are not realistic, as we believe Discouraged Immigrants who did not arrive in the U.S. on account of declining pull-factors specific to the U.S., such as declining labor demand, should not be more likely to find employment than the general population.

One possible concern with the analysis presented in the paper is that the inclusion of the year 2013 in the regression may distort our results. We repeated all analyses excluding 2013; additional robustness check tables and figures for each step are available upon request from the authors. The final results of this robustness check are displayed as a check of Figure 3 in the paper. The left panel of Figure A4 displays the change in EPOP year by year with the year 2013 omitted from the regression as a robustness check, while the right panel compares across growth rates the total decline between 2000 and 2013. We find that omitting 2013 from the regression yields nearly identical results. 


\section{Supplemental Tables:}

Table A1: Census Data

\begin{tabular}{rrrrr}
\hline \hline & \multicolumn{4}{c}{ Annual Growth } \\
Year & Immigrant Population & Raw & Rate & $\Delta$ Rate \\
\hline 1870 & $4,705,889$ & & & \\
1880 & $5,795,406$ & 108,952 & 0.0208 & \\
1900 & $9,432,960$ & 181,878 & 0.0244 & 0.0035 \\
1910 & $11,907,210$ & 247,425 & 0.0233 & -0.0011 \\
1920 & $12,871,153$ & 96,394 & 0.0078 & -0.0155 \\
1930 & $13,380,379$ & 50,923 & 0.0039 & -0.0039 \\
1940 & $11,374,902$ & $-200,548$ & -0.0162 & -0.0201 \\
1950 & $10,322,194$ & $-105,271$ & -0.0097 & 0.0065 \\
1960 & $9,031,543$ & $-129,065$ & -0.0134 & -0.0036 \\
1970 & $9,018,800$ & $-1,274$ & -0.0001 & 0.0132 \\
1980 & $12,842,480$ & 382,368 & 0.0353 & 0.0355 \\
1990 & $18,702,511$ & 586,003 & 0.0376 & 0.0022 \\
2000 & $29,555,705$ & $1,085,319$ & 0.0458 & 0.0082 \\
2013 & $40,911,908$ & 873,554 & 0.0250 & -0.0208 \\
\hline \hline
\end{tabular}


Table A2: Sending Countries Analysis: Regression Including 2013

\begin{tabular}{|c|c|c|c|c|c|}
\hline & & \multicolumn{2}{|c|}{ Distance Weights } & \multicolumn{2}{|c|}{ No Distance Weights } \\
\hline Birthplace & Persons & Betas & P-Values & Betas & P-Values \\
\hline Mexico & $8,161,971$ & 2.1816 & 0.003 & 2.2157 & 0.003 \\
\hline Other & $2,926,678$ & 0.4157 & 0.053 & 0.3546 & 0.055 \\
\hline China & $1,435,441$ & 1.7202 & 0.002 & 1.4736 & 0.002 \\
\hline Vietnam & $1,402,613$ & 3.4719 & 0.050 & 3.0884 & 0.045 \\
\hline Philippines & $1,340,595$ & 1.5989 & 0.009 & 1.5048 & 0.009 \\
\hline Germany & $1,040,327$ & 0.1735 & 0.000 & 0.1321 & 0.000 \\
\hline India & 951,485 & 2.4683 & 0.002 & 2.0124 & 0.001 \\
\hline Canada & 844,505 & 0.0191 & 0.728 & 0.0188 & 0.735 \\
\hline Cuba & 835,183 & 0.6523 & 0.006 & 0.7400 & 0.005 \\
\hline Korea & 790,569 & 2.0774 & 0.024 & 1.9232 & 0.022 \\
\hline El Salvador & 768,769 & 3.0606 & 0.013 & 3.5134 & 0.015 \\
\hline England & 625,611 & 0.2971 & 0.003 & 0.2242 & 0.008 \\
\hline Dominican Rep. & 622,329 & 2.0028 & 0.003 & 2.1417 & 0.003 \\
\hline USSR/Russia & 522,212 & 0.8296 & 0.387 & 0.6830 & 0.395 \\
\hline Jamaica & 518,216 & 1.5448 & 0.005 & 1.7127 & 0.005 \\
\hline Italy & 510,289 & -0.5228 & 0.001 & -0.4069 & 0.002 \\
\hline Colombia & 468,099 & 1.6754 & 0.002 & 1.8395 & 0.003 \\
\hline Poland & 451,933 & -0.0480 & 0.682 & -0.0450 & 0.603 \\
\hline Guatemala & 442,132 & 2.5130 & 0.001 & 2.9245 & 0.001 \\
\hline Japan & 424,899 & 0.8152 & 0.016 & 0.7830 & 0.016 \\
\hline Haiti & 388,820 & 2.0445 & 0.004 & 2.2161 & 0.004 \\
\hline Venezuela & 298,267 & 2.3491 & 0.014 & 2.5132 & 0.014 \\
\hline Iran & 280,472 & 1.7757 & 0.027 & 1.4036 & 0.018 \\
\hline Ecuador & 273,680 & 1.7120 & 0.001 & 1.9155 & 0.001 \\
\hline Honduras & 259,501 & 2.5075 & 0.000 & 2.8987 & 0.000 \\
\hline Peru & 256,701 & 1.9980 & 0.001 & 2.1925 & 0.001 \\
\hline Nigeria & 256,497 & 2.7456 & 0.007 & 2.3284 & 0.004 \\
\hline Nicaragua & 209,078 & 1.9192 & 0.014 & 2.2037 & 0.017 \\
\hline Pakistan & 201,105 & 2.7545 & 0.005 & 2.2113 & 0.003 \\
\hline Brazil & 195,061 & 1.9228 & 0.000 & 1.9820 & 0.000 \\
\hline Trinidad \& Tobago & 186,483 & 1.6822 & 0.011 & 1.7669 & 0.010 \\
\hline France & 177,839 & 0.4145 & 0.003 & 0.3127 & 0.001 \\
\hline Portugal & 176,514 & 0.4387 & 0.164 & 0.3683 & 0.125 \\
\hline Greece & 172,334 & -0.0845 & 0.403 & -0.0556 & 0.472 \\
\hline Ireland & 152,319 & -0.3518 & 0.003 & -0.2736 & 0.002 \\
\hline Panama & 129,197 & 1.0798 & 0.030 & 1.2230 & 0.032 \\
\hline Romania & 121,780 & 0.5882 & 0.018 & 0.4190 & 0.031 \\
\hline Argentina & 119,452 & 0.9552 & 0.002 & 1.0311 & 0.002 \\
\hline Israel/Palestine & 108,570 & 0.9286 & 0.005 & 0.7205 & 0.002 \\
\hline Egypt & 107,394 & 1.3608 & 0.000 & 1.0616 & 0.000 \\
\hline Lebanon & 106,860 & 1.1939 & 0.017 & 0.9293 & 0.009 \\
\hline Spain & 104,880 & 0.5062 & 0.000 & 0.3937 & 0.000 \\
\hline Netherlands & 96,353 & -0.0292 & 0.182 & -0.0225 & 0.156 \\
\hline Scotland & 92,692 & -0.4550 & 0.000 & -0.3396 & 0.001 \\
\hline
\end{tabular}


Table A3: Counterfactuals Under Different Assumptions

\begin{tabular}{rrrrrr}
\hline \hline Pull & Imm 2013 & CF Imm 2013 & Missing & Alpha & Miss Emp \\
\hline Pull (Distance Weights) & 41,308 & 48,535 & 7,227 & 0.00 & 0 \\
Pull (Distance Weights) & 41,308 & 48,535 & 7,227 & 0.10 & 723 \\
Pull (Distance Weights) & 41,308 & 48,535 & 7,227 & 0.20 & 1,445 \\
Pull (Distance Weights) & 41,308 & 48,535 & 7,227 & 0.30 & 2,168 \\
Pull (Distance Weights) & 41,308 & 48,535 & 7,227 & 0.40 & 2,891 \\
Pull (Distance Weights) & 41,308 & 48,535 & 7,227 & 0.50 & 3,614 \\
Pull (Distance Weights) & 41,308 & 48,535 & 7,227 & 0.58 & 4,228 \\
Pull (Distance Weights) & 41,308 & 48,535 & 7,227 & 0.70 & 5,059 \\
\hline Pull (No-Distance Weights) & 41,308 & 49,320 & 8,012 & 0.00 & 0 \\
Pull (No-Distance Weights) & 41,308 & 49,320 & 8,012 & 0.10 & 801 \\
Pull (No-Distance Weights) & 41,308 & 49,320 & 8,012 & 0.20 & 1,602 \\
Pull (No-Distance Weights) & 41,308 & 49,320 & 8,012 & 0.30 & 2,404 \\
Pull (No-Distance Weights) & 41,308 & 49,320 & 8,012 & 0.40 & 3,205 \\
Pull (No-Distance Weights) & 41,308 & 49,320 & 8,012 & 0.50 & 4,006 \\
Pull (No-Distance Weights) & 41,308 & 49,320 & 8,012 & 0.58 & 4,687 \\
Pull (No-Distance Weights) & 41,308 & 49,320 & 8,012 & 0.70 & 5,609 \\
\hline Raw (Push and Pull) & 41,308 & 54,099 & 12,791 & 0.00 & 0 \\
Raw (Push and Pull) & 41,308 & 54,099 & 12,791 & 0.10 & 1,279 \\
Raw (Push and Pull) & 41,308 & 54,099 & 12,791 & 0.20 & 2,558 \\
Raw (Push and Pull) & 41,308 & 54,099 & 12,791 & 0.30 & 3,837 \\
Raw (Push and Pull) & 41,308 & 54,099 & 12,791 & 0.40 & 5,116 \\
Raw (Push and Pull) & 41,308 & 54,099 & 12,791 & 0.50 & 6,396 \\
Raw (Push and Pull) & 41,308 & 54,099 & 12,791 & 0.58 & 7,483 \\
Raw (Push and Pull) & 41,308 & 54,099 & 12,791 & 0.70 & 8,954 \\
\hline \hline
\end{tabular}


Table A4: Counterfactuals Under Different Assumptions

\begin{tabular}{rrrrrrr}
\hline \hline Pull & Alpha & EPOP & CF EPOP & EPOP $_{d}$ & CF EPOP $_{d}$ & Ratio \\
\hline Pull (Distance Weights) & 0.00 & 58.50 & 56.81 & -6.10 & -7.79 & 1.28 \\
Pull (Distance Weights) & 0.10 & 58.50 & 57.10 & -6.10 & -7.50 & 1.23 \\
Pull (Distance Weights) & 0.20 & 58.50 & 57.39 & -6.10 & -7.21 & 1.18 \\
Pull (Distance Weights) & 0.30 & 58.50 & 57.67 & -6.10 & -6.93 & 1.14 \\
Pull (Distance Weights) & 0.40 & 58.50 & 57.96 & -6.10 & -6.64 & 1.09 \\
Pull (Distance Weights) & 0.50 & 58.50 & 58.25 & -6.10 & -6.35 & 1.04 \\
Pull (Distance Weights) & 0.58 & 58.50 & 58.49 & -6.10 & -6.11 & 1.00 \\
Pull (Distance Weights) & 0.70 & 58.50 & 58.82 & -6.10 & -5.78 & 0.95 \\
\hline Pull (No-Distance Weights) & 0.00 & 58.50 & 56.64 & -6.10 & -7.96 & 1.31 \\
Pull (No-Distance Weights) & 0.10 & 58.50 & 56.96 & -6.10 & -7.64 & 1.25 \\
Pull (No-Distance Weights) & 0.20 & 58.50 & 57.27 & -6.10 & -7.33 & 1.20 \\
Pull (No-Distance Weights) & 0.30 & 58.50 & 57.59 & -6.10 & -7.01 & 1.15 \\
Pull (No-Distance Weights) & 0.40 & 58.50 & 57.90 & -6.10 & -6.70 & 1.10 \\
Pull (No-Distance Weights) & 0.50 & 58.50 & 58.22 & -6.10 & -6.38 & 1.05 \\
Pull (No-Distance Weights) & 0.58 & 58.50 & 58.49 & -6.10 & -6.11 & 1.00 \\
Pull (No-Distance Weights) & 0.70 & 58.50 & 58.85 & -6.10 & -5.75 & 0.94 \\
\hline Raw (Push and Pull) & 0.00 & 58.50 & 55.59 & -6.10 & -9.01 & 1.48 \\
Raw (Push and Pull) & 0.10 & 58.50 & 56.09 & -6.10 & -8.51 & 1.40 \\
Raw (Push and Pull) & 0.20 & 58.50 & 56.58 & -6.10 & -8.02 & 1.31 \\
Raw (Push and Pull) & 0.30 & 58.50 & 57.08 & -6.10 & -7.52 & 1.23 \\
Raw (Push and Pull) & 0.40 & 58.50 & 57.57 & -6.10 & -7.03 & 1.15 \\
Raw (Push and Pull) & 0.50 & 58.50 & 58.07 & -6.10 & -6.53 & 1.07 \\
Raw (Push and Pull) & 0.58 & 58.50 & 58.49 & -6.10 & -6.11 & 1.00 \\
Raw (Push and Pull) & 0.70 & 58.50 & 59.06 & -6.10 & -5.54 & 0.91 \\
\hline \hline
\end{tabular}


Supplemental Figures:

Figure A1: Log Immigrant Stock: 1870-2013

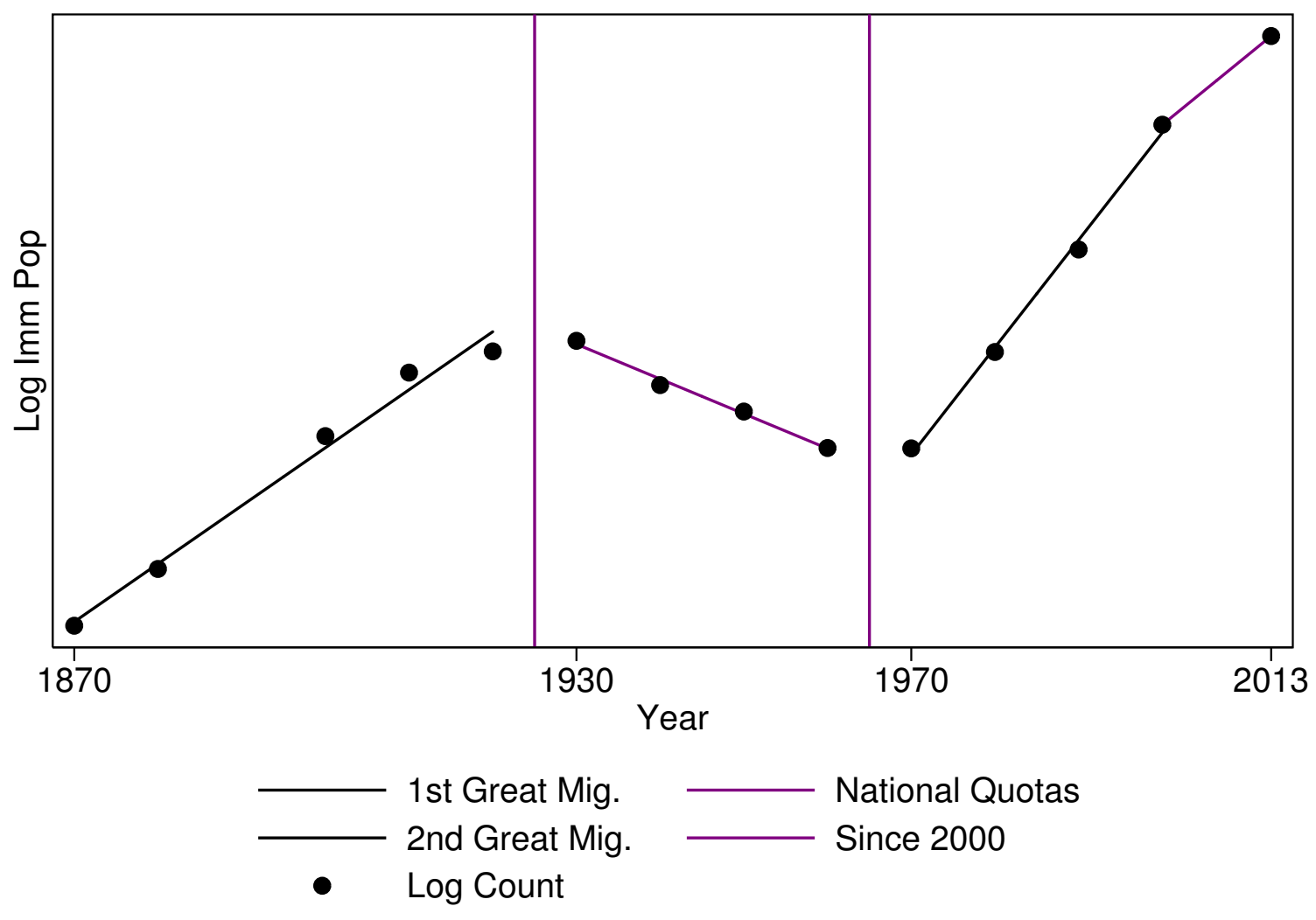


Figure A2: Distribution of P-Values from Migration Stock Regressions
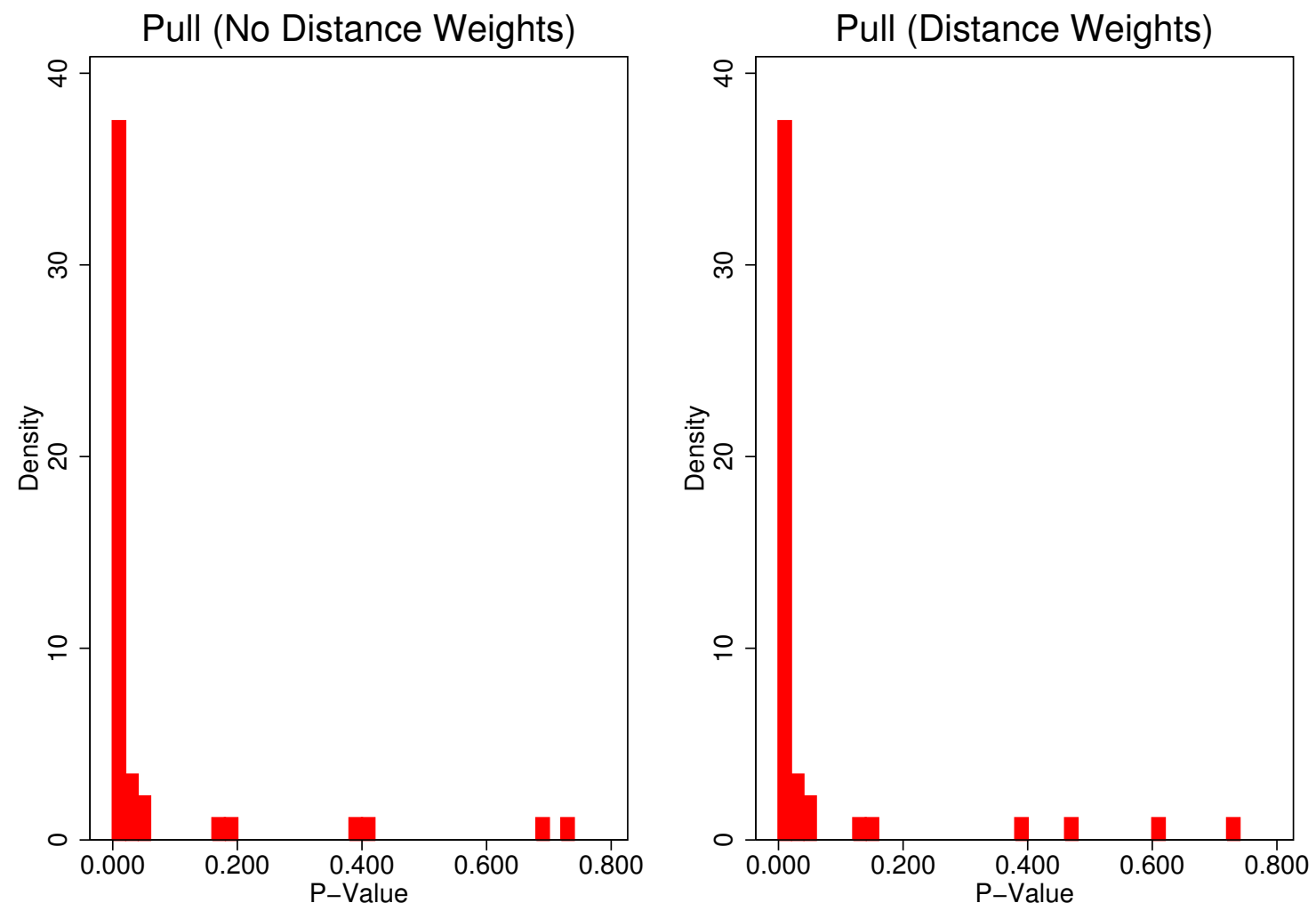
Figure A3: Decline in EPOP Since 2000 (Relative to Base Decline)

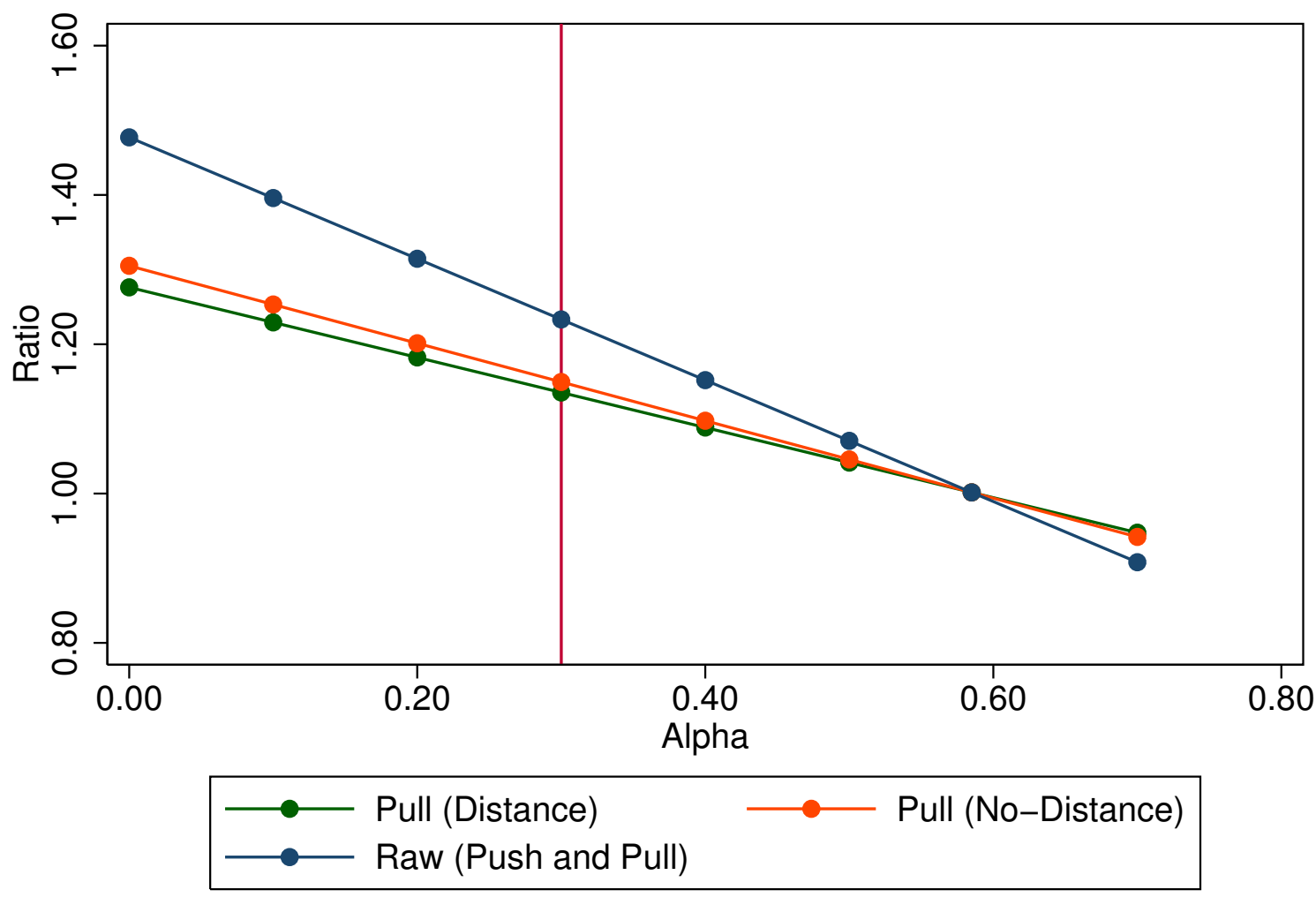

Source: ACS 
Figure A4: Baseline and Counterfactual Changes in EPOP - 2013 Omitted
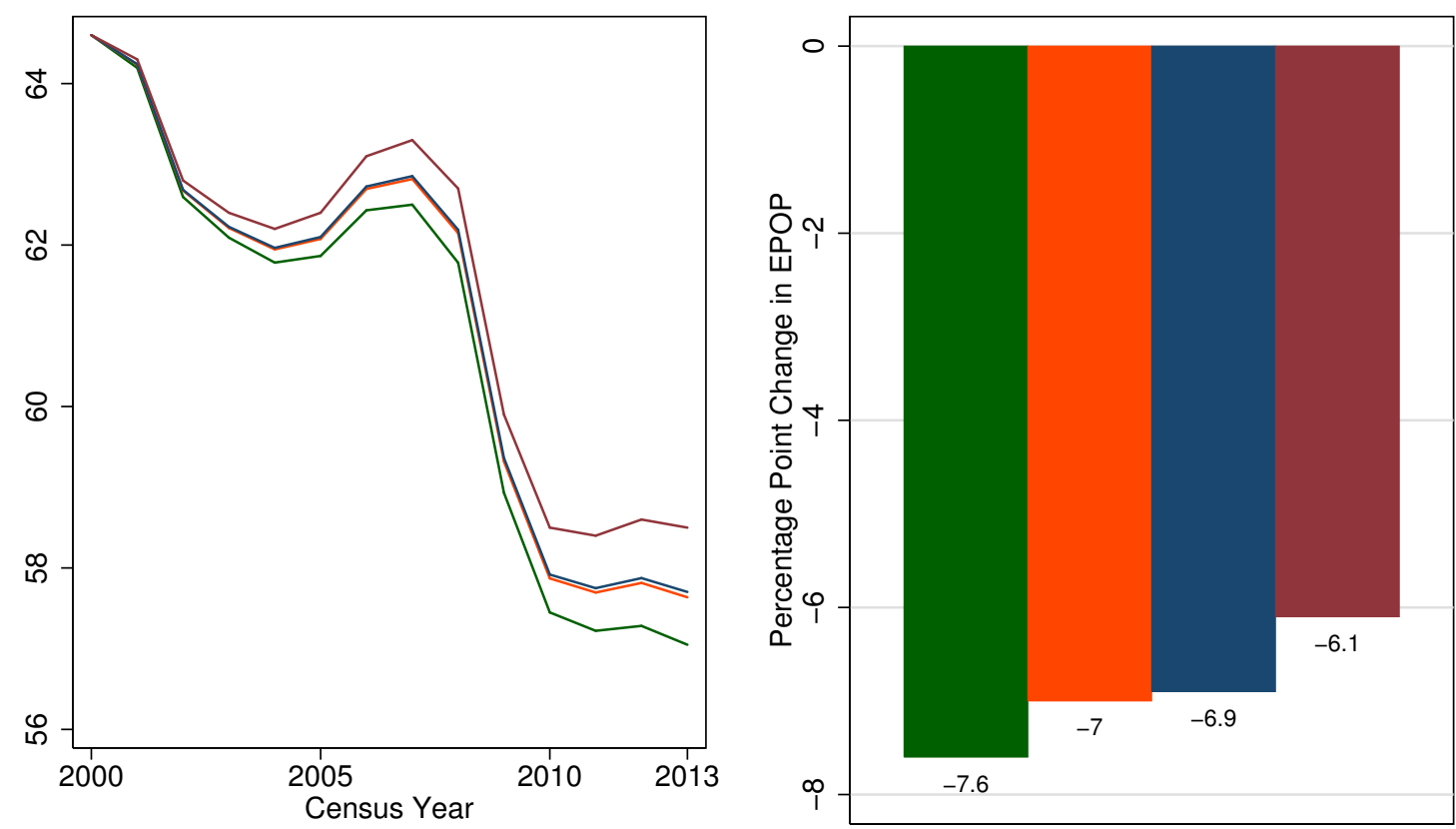

CF: 1990s Trend CF: Pull Driven (No Distance)

CF: Pull Driven (Distance) Observed EPOP

Source: ACS and BLS. 


\section{References}

Grasland, Claude and Malika Madelin, "The unequal distribution of population and wealth in the world," Population et Sociétés, 2001, (368), 1-4.

Passel, Jeffrey S., Cohn D'Vera, and Ana Gonzalez-Barrera, "Population Decline of Unauthorized Immigrants Stalls, May Have Reversed," Pew Hispanic Center, 2013.

Ruggles, Steven, J. Trent Alexander, Katie Genadek, Ronald Goeken, Matthew B. Schroeder, and Matthew Sobek, "Integrated Public Use Microdata Series: Version 5.0 [Machine-readable database]," 2010. 